Este trabalho apresenta a clínica das psicoses como uma experiência limite, em que é necessária uma série de atos analíticos para criar as condições do tratamento. Descreve os diversos momentos clínicos e aborda os efeitos estruturais da análise para as psicoses ño decididas da infância. Apresenta ainda os impasses desta clínica, por meio de um caso paradigmático. Psicose na infância; ato analítico; tratamento psicanalítico

THE CLINIC OF INFANTILE PSYCHOSIS: IMPASSES AND INVENTIONS

This paper presents the psychosis clinic as an experience-limit in which a chain of analyticals actings is necessary to create the treatment conditions. It describes the several clinical moments and approaches the structural effects of the psychoanalysis to the non-decided infantile psychosis. It also presents the impasses in this clinic through a paradigmatic case. Infantile psychosis; analytical acting; psychoanalytical treatment

\section{A CLÍNICA DAS \\ PSICOSES NA INFÂNCIA: IMPASSES E INVENÇÕES}

Leda Mariza Fischer Bernardino

nquanto psicanalistas, temos uma abordagem estrutural da questão das psicoses na infância. Seguimos um caminho desbravado por nossos antecessores. Freud descobriu o valor das palavras, da instauração da transferência e dos mecanismos defensivos que marcam nossa instalação na linguagem, abrindo o caminho para um diagnóstico estrutural. Melanie Klein nos mostrou que a criança, e mesmo a criança psicótica, pode ser receptiva aos efeitos destas palavras. Winnicott apontou-nos o campo da ilusão e da transicionalidade como essenciais para o surgimento de um sujeito. Lacan, por sua vez, abriu as possibilidades de uma clínica do significante, não necessariamente verbal. Françoise Dolto desdobrou as conseqüências disto na escuta das crianças em situação de risco e de seus pais. Maud Mannoni ampliou as alternativas de atendimento mostrando suas possibilidades institucionais. Enfim, não nos faltam referências teóricas e práticas neste campo.

Apesar desse trilhamento, a cada vez que nos lançamos nessa clínica, sabemos tratar-se de uma experiência-limite, em que o conhecimento, a experiência

\footnotetext{
Psicanalista, presidente da Associação Psicanalítica de Curitiba, doutora em Psicologia Escolar e do Desenvolvimento Humano pela USP.
} 
e a análise são apenas um ponto de partida, pois não temos idéia do caminho que faremos a cada vez, nem sabemos muito bem aonde vai dar. É uma clínica temerária: sabemos que implica riscos, mas não sabemos quais serão.

A escuta das crianças que são assim diagnosticadas e que recebemos para tratamento representa um desafio. Enfrentar este desafio pressupõe que teremos de apostar. Por isso, tomando como inspiração Marie-Christine Laznik-Penot - quando fala da clínica do autismo como uma clínica ao avesso, pelo trabalho de construção que aí se produz, em contraponto à desconstrução esperada de uma análise tradicional -, arrisco-me a dizer que há uma outra inversão que é necessário produzir: um só-depois que tem de estar posto de saída. Assim, proponho que, nesta clínica das psicoses na infância e do autismo, os atos analíticos devem ser postos a priori, para fundar a possibilidade da análise primeiramente do lado do analista, para testemunhar de seu desejo de conduzir este processo. Só-depois de vários atos analíticos desta ordem é que se poderá instaurar uma análise propriamente dita, quando ela chega a se produzir.

Primeiramente, ao recebermos o novo paciente com esse diagnóstico, apostamos que há um sujeito em constituição ali, por mais longínqua que esta hipótese possa parecer. Apostamos nosso desejo nisto: fazemos da antecipação subjetiva nosso primeiro ato analítico para com a criança.

Em segundo lugar, e conseqüentemente, apostamos que este pequeno sujeito a surgir será permeável aos efeitos das palavras. Apostamos nossa enunciação nisto: não importa o que ou como o digamos, nosso segundo ato analítico para com estes pequenos pacientes é uma chamada à fala, um convite à possibilidade de apropriação da linguagem.

A terceira aposta que fazemos é no brincar e na instauração de um campo lúdico entre nós e a criança. Queremos encantá-la com o faz-de-conta que povoa o universo infantil. Nosso terceiro ato analítico é escolher um objeto, seja qual for, que nos pareça dizer respeito ao que já ouvimos/percebemos da criança, como um atributo possível para the oferecer, que a represente além de seu corpo real, numa iniciação ao Imaginário.

Uma quarta aposta é nossa "prontidão para a leitura": estamos sempre dispostos a ler, no menor risco, traçado, ou simples garatuja, uma marca, uma letra, um desenho, que testemunhe da passagem da criança por ali. Nosso quarto ato analítico é tomar estas marcas como formas, escrituras, histórias, que nos são dirigidas enquanto mensagens a decifrar.

Finalmente, uma vez as apostas feitas, jogamos nossa primeira cartada: tentamos penetrar neste mundo aparentemente a-simbólico, 
marcando-o com um não, enunciamos um limite, alguma interdição, que pode ser referente a uma demarcação no espaço físico, a alguma ação ou simplesmente ao corpo da criança. Pode até mesmo marcar um limite pessoal: aquilo que nos é impossível suportar. Um limite qualquer que interrompa o gozo - a passividade do ser/estar objeto - e provoque perplexidade, isto é, rompimento de significações. É o momento em que podemos interpretar: a criança subitamente nos olha, nos percebe, acusa recebimento. Propomos fazer do signo que esta criança é para seu outro - enquanto única verdade possível, e que é prisão - uma disjunção, tentando separar a colagem S1 e S2, para inaugurar o deslizamento significante.

Se a esse primeiro lance do jogo seguem-se respostas, é sinal de que a criança deu abertura para nossa presença em seu mundo e, assim, aceitou jogar o jogo. Somos então, qual principezinho perante a flor ${ }^{1}$, eternamente responsáveis por aquela que cativamos: porque a fizemos penetrar no cativeiro da linguagem..., sem o qual nossa liberdade seria só loucura, como apontou Lacan.

Começa o jogo. Como defini-lo? Quais são suas regras, seu objetivo? Vai haver vencedor?

Não há instruções: o jogo vai se montando na medida do jogar. Sessão após sessão, trataremos de construir, com os materiais que se apresentam (no discurso dos pais, nos significantes da criança, no seu fazer ou no seu dizer), as diferentes operações psíquicas que constituem um sujeito, que permitem sua inserção no mundo humano, primei- ramente na família e depois no campo social.

Tomando cada qual na sua particularidade, vamos percorrer com estes analisantes um caminho no qual esperamos promover:

- A construção de um mito de origem, ponto de partida simbólico, em que os significantes familiares permitem deduzir um determinado lugar, tanto na família quanto nas gerações.

- A construção do pequeno outro, quando o analista, enquanto parceiro imaginário, serve de referência especular de identificação, intermediando o anonimato da função do Outro.

- A construção de uma imagem corporal torna-se então possível: o corpo deixa de ser real, puro objeto devido ao Outro, para se tornar uma referência imaginária e um esquema simbólico de sustentação egóica.

- Finalmente, esperamos que o processo venha a desembocar na construção de um Outro. Faltante, desejante, enigmático, instigador das perguntas fundamentais: quem sou eu?/quem sou eu para o Outro/que quer ele de mim?

Talvez pudéssemos dizer que o objetivo do jogo é justamente este: deparar com uma falta e encontrar o desejo como enigma, e poderíamos chamá-lo de Édipo.

Teria esse jogo uma definição do vence-dor? Seria aquele que abandona o gozo de ser... objeto, para suportar dividir-se entre a dor e a delícia de viver, ou seja, para desejar... verbo intransitivo?

Nem sempre o jogo se presta a esse mesmo itinerário, nem tampou- 


\section{Artigo}

co ele é linear. A análise pode ser o lugar de inventar um outro jogo, mais particular, uma construção um pouco diferente das outras, que tenta cobrir com cimento (Imaginário) as rachaduras (Simbólicas) dos alicerces. Isto permite manter-se num jogo ou, na iminência da saída, saber reconstruí-lo segundo esta experiência.

Referimo-nos às duas possibilidades de evolução de uma psicose-não decidida (que é como pensamos toda psicose, na infância), a partir de um tratamento psicanalítico:

1) a possibilidade de construção de uma metáfora paterna, que permite a definição da estrutura no sentido de uma escolha sintomática neurótica; ou, na impossibilidade disto,

2) a construção de uma metáfora delirante, que permite a uma estrutura psicótica elaborar um outro tipo de amarração que não a fálica, mas que segura a circulação num mundo fálico.

Com isso estamos afirmando que os efeitos de uma análise para uma criança, diagnosticada como psicótica, quando há realmente análise, são sempre estruturais.

Conduzir esse jogo não é tarefa fácil - a transferência real que aí entra em jogo nem sempre é suportável. Nesta clínica, são freqüentes as ocorrências de danos fisicos (analistas que recebem tapas, chutes, mordidas, que são alvos de objetos, que são derrubados literalmente); sem falar nos danos aos materiais (brinquedos quebrados, paredes pintadas, chão do consultório estragado, roupas rasgadas, pintadas); ou nos que atingem o interior do corpo (resultados psicossomáticos, para o analista, dos efeitos do 
trabalho). Na maioria das vezes, é uma clínica bem pouco discreta: são comuns os gritos, os barulhos fortes, as irrupções no consultório invadindo os horários de outros pacientes, os "escândalos" na sala de espera, no saguão.

Enfim, como num jogo de azar, a cada novo encontro é preciso refazer novamente as apostas, sendo aconselhável ter "uma carta na manga" para as surpresas do percurso.

Poderíamos nos perguntar, continuando a analogia com o jogo: com que capital o analista aposta, afinal? A resposta é: sua subjetividade. Estes tratamentos são movidos fundamentalmente pelo nosso desejo. Sem ele, não haveria fichas para jogar, e só restariam a criança-objeto e o adulto que está preso com ela neste gozo louco e fora-de-jogo.

Se é do desejo do analista que se trata, cabe uma questão ética: o que sustentaria nosso desejo, que, supomos, já foi suficientemente analisado para se colocar fora do circuito neurótico do "desejo de curar" inicial que nos impulsionou a jogar?

Responderíamos que é nossa própria transferência para com a psicanálise, que nos faz buscar - no pequeno sujeito em perigo - o encantamento da descoberta da palavra, que abre para o "jogo da vida".

Mas nem só de encantos, como vimos, se compõe nossa prática. E, como sugeria Lacan, convém estarmos advertidos do que encontraremos pela frente, no que se refere ao desejo do analista. Poder se autorizar enquanto tal passa por uma formação que deve muito à clínica de crianças e à clínica das psicoses. Os impasses da clínica psicanalítica com crianças psicóticas permitem repensar esta trajetória.

Desenvolveremos esse ponto a partir de uma pequena história, que pretendemos tomar não em seu detalhamento, e sim como paradigma desta clínica. Trata-se da história do tratamento de uma criança psicótica, que se iniciou há quinze anos.

A história se passa tendo como cenário uma instituição pública, em que coube à analista substituir uma outra profissional e dar continuidade aos tratamentos que esta iniciara. Esta profissional, como ficou logo evidente, seguia uma abordagem psicomotora convencional.

O protagonista dessa história, Adão, é um menino de 6 anos, que vem, junto com sua mãe, para uma primeira entrevista. Ele iniciara o trabalho aos 3 anos, devido à "hiperatividade". Observo que ele não consegue expressar-se: suas frases são incompletas, feitas de palavras desconexas, é muito difícil compreendê-lo. Além disso, não se detém em nenhuma atividade espontaneamente, embora a mãe relatasse que ele realizava bem os exercícios propostos pela terapeuta anterior. 


\section{Artigo}

É verdade que Adão apresentava hiperatividade, falta de coordenação e de orientação no tempo e no espaço. Mas estas eram as menores das suas dificuldades, na medida em que ele não sabia nada sobre si e tampouco sua família conseguia the propor algo. Sua mãe era uma mulher frágil, depressiva e extremamente ligada a ele, representante de sua infância perdida e inenarrável. Seu pai, classicamente ausente, era detentor de um discurso de estilo paranóico que encontrava boa acolhida em suas atividades políticas num órgão de classe.

Detenhamo-nos um momento aqui para refletir. Um primeiro impasse já pode ser apontado como paradigmático desta clínica das psicoses na infância: a imprecisão do diagnóstico, que, ao não detectar as características psicóticas, não indica os riscos psíquicos a que está exposta a criança, impelindo-a, e aos seus responsáveis, para tratamentos que visam alguns sintomas, os mais aparentes e menos adaptados, que acabam produzindo efeitos iatrogênicos, pois promovem uma fixidez das defesas e confirmam os mecanismos psicóticos.

Deparamos aí também com a falta de transferência no campo médico, psiquiátrico, dos profissionais de saúde mental em geral, para com o discurso psicanalítico e para com a psicanálise como alternativa terapêutica nos casos de psicose na infância. Por trás de argumentos como alto custo, demora em produzir resultados, não indicação para casos mais graves, que demonstram um desconhecimento do que se tem publicado a respeito na literatura psicanalítica nos últimos setenta anos, o saber médico faz parceria com o discurso neoliberal, ao serviço da adaptação e mecanização do homem, em detrimento da valorização dos aspectos subjetivos, que fazem o elemento humano enquanto tal.

No caso de Adão, tratava-se de uma criança de 6 anos, inteligente, ativa e extremamente criativa graficamente, que apresentava sintomas psicóticos de desconexão, dificuldades de relacionamento interpessoal, uso ecolálico da linguagem e delírio psicomotor, ao mesmo tempo que uma abertura para as intervenções do Outro e uma possibilidade de fazer apelo ao Outro por meio de suas produções. Poderíamos falar em uma psicose não-decidida: ele se apresentava, na transferência, ora numa posição psicótica, ora numa posição neurótica.

Essa criança passara três anos de sua vida, anos fundamentais em termos dos aspectos instrumentais e estruturais do seu desenvolvimento, fazendo exercícios de lateralidade, de esquema corporal, de percepção, etc., sem que ninguém fosse ouvido quanto ao seu lugar na família, sem que se questionasse seu desejo (justamente o motor de todo desenvolvimento) e muito menos houvesse uma preocupa- 
ção em lhe dar um lugar de palavras, de falasser!

O neuropediatra que o avaliara inicialmente, quando procurado pela analista para uma interconsulta, mostrou o laudo que elaborara, evidenciando a perplexidade que Adão lhe provocara: por conta da hiperatividade, ele indicara uma lista variada de prescrições, que ia da medicação tranqüilizante aos atendimentos em psicologia, fonoaudiologia, psicomotricidade, psicopedagogia, até natação e judô!

Foi possível, por esse contato, propor uma nova direção ao tratamento de Adão, com a concordância relutante do neuropediatra, um tanto quanto céptico sobre o alcance de um trabalho com as palavras.

Podemos situar aí um outro impasse: a deficiência na formação dos profissionais que trabalham com a saúde mental e que não têm um conhecimento da psicose fora dos critérios nosográficos da psiquiatria tradicional, que propõe uma listagem de sintomas patognomônicos, de medicamentos a eles dirigidos, e muito pouco no que se refere a um atendimento clínico. Estes profissionais desconhecem a psicose enquanto estrutura, bem como a imensa literatura que vem descrevendo, desde a época de Melanie Klein (1930), as possibilidades de intervenção mediante a psicanálise, até os dias de hoje, quando dispomos de uma vasta bibliografia discutindo o diagnóstico, o tratamento e o prognóstico para estes casos. Nas interconsultas, deparamos com uma carência conceitual e de leituras, que impedem uma linguagem mínima comum. Acabamos no papel do "catequista" que tenta explicar aos não iniciados nos conceitos psicanalíticos os benefícios de uma "cura pela palavra", tendo de contar com a boa vontade do interlocutor, muitas vezes perplexo diante desta alternativa, dirigida a crianças que muitas vezes nem reagem aos sons. Podemos, com o tempo e após alguns seguimentos de casos em conjunto, ser bem-sucedidos nesta empreitada e contar com alguns interlocutores. Entretanto, restam os que não estão disponíveis para esta troca, infelizmente um grande número hoje em dia, e que continuam encaminhando as crianças - que recebem às vezes precocemente $e$ ainda com defesas incipientes - para a alternativa de tratamento que está na moda no momento...

Retomemos a trajetória de Adão, que com 6 anos iniciou seu tratamento psicanalítico. Não sem antes enfrentarmos muita resistência por parte dos pais, tomados de surpresa pelo questionamento do tratamento anterior. Agora eram chamados a se colocar e a contar sua história, o que nem sempre era fácil. A mãe teve mais disponibilidade, na medida em que descobriu, neste contexto, um filho que dizia alguma coisa compreensivel e the fazia apelos; e também por ter encontrado um terceiro apaziguador na sua relação dificil com este filho. Quanto ao pai, por sua vez, armou defesas maciças para não abalar suas certezas e apenas concordou em que o trabalho ocorresse, embora sem muita disposição para dar lugar a este filho.

Temos nesse ponto um dos impasses mais importantes dessa clínica: 
a participação dos pais e sua abertura ao trabalho. $\mathrm{O}$ tratamento de crianças que se encontram num lugar psicótico avança na medida das possibilidades de falta por parte de seus pais. Se os outros parentais não se dispõem minimamente a questionar o lugar que vem sendo dado ao filho, o encaminhamento para a psicose é incontornável. No caso de Adão, era muito difícil para seus pais entenderem algo de seu sofrimento e lhe concederem um lugar de sujeito.

Contudo, Adão foi conquistando um lugar outro no setting analítico, principalmente por meio de seus desenhos, que eram surpreendentes: inicialmente, tratava-se de personagens em cenas de perigo, na beira do precipício, no meio de um incêndio, quase caindo de um prédio, que ilustravam bem sua posição. Eram desenhos que despertavam a atenção pelo movimento que ele conseguia imprimir às figuras. Ao formular em palavras o sofrimento das personagens que ele desenhava, ao pôr alguma ordem nas palavras soltas que ele largava ao léu, a analista foi permitindo que Adão pudesse paulatinamente se reconhecer como falante. Ele reagiu prontamente, passando pouco a pouco a se expressar com frases inteligíveis. A mãe, a partir deste reconhecimento, começou a reconhecer este filho, não mais como pedaço de carne e fonte de problemas, mas como alguém para quem era possível fazer planos.

Com suas condições melhorando, chegou o momento de Adão freqüentar a escola. Novo impasse aparece: como encontrar entre os pares e no ambiente escolar um lugar para sua diferença? Novamente é o momento da interconsulta - desta vez um diálogo com o campo da educação. Uma orientação se fez necessária para as diversas professoras que Adão foi encontrando no seu percurso educativo. Adão foi alfabetizado sem problemas, mas tinha muitas dificuldades em matemática. Poder ouvir as professoras e acolher seu espanto diante desta criança "diferente" foi essencial para que elas pudessem reconhecer nele um aluno e trabalhar para sua integração junto aos colegas. Sem esta assessoria, seria mais provável que Adão fosse marginalizado, ou mesmo afastado da escola. Enquanto analistas, não podemos nos poupar deste trânsito no campo social, em que somos chamados a dar conta de nossa prática e a intervir para garantir a seqüência do tratamento.

Cinco anos após iniciarmos a análise, em função do desligamento da analista da instituição, tivemos que interrompê-la. Os pais alegaram não ter condições de pagar um tratamento em consultório, mesmo tendo ficado aberta a possibilidade de negociação do preço.

Três anos depois, quando Adão estava com 14 anos, sua mãe voltou a demandar uma análise para ele, que vinha fazendo reiterados pedidos neste sentido. A família estava em crise após a sepa- 
ração do casal. Seu pai, embora tivesse uma situação financeira melhor, em virtude de suas conquistas profissionais, relutava bastante em pagar este trabalho.

Reiniciamos a análise, agora de um adolescente: Adão se coloca prioritariamente pela fala, embora ainda desenhe bastante. Faz pequenas histórias em quadrinhos, em que se trata de questões de comparação entre homem e mulher, entre um amigo e outro, questões sobre origem, sobre trabalho. Mas seus personagens já não têm mais aquele movimento que ele conseguia imprimir quando criança. Adão intercala relatos de seu cotidiano - relações com amigos, garotas, professores -, com alguns temas delirantes - por exemplo, uma "coleção de ossos” que está fazendo em sua biblioteca. Observamos a psicose se definindo como estrutura. Seu pai, apesar de seus apelos, o abandona francamente, embora continue a se relacionar bem com os outros filhos. Adão tem uma irmã mais velha $e$ um irmão mais novo que passeiam com o pai, estudam em escola particular, ganham roupas... enquanto ele estuda em escola pública e mal consegue pagar sua análise. Depois de um ano, Adão decide interromper as sessões: é-lhe muito pesado não poder pagar por elas.

Desde então, Adão passa ocasionalmente no consultório da analista para "dar notícias". Hoje está com 21 anos, continua a estudar num colégio público e, apesar da defasagem de algumas séries em relação aos colegas, tem alguns amigos. Da última vez que fez uma "visita", contou um episódio traumático que vivera 
um ano antes, quando se sentira injustiçado em relação à atitude de um professor: decidira vir dizer à analista o quanto isto o abalara, pois ainda não comentara o fato com ninguém. Quando de outra visita anterior, por exemplo, veio para relatar que um colega morrera num acidente.

Vejamos o que a trajetória de Adão, mais além da sua singularidade, pode nos apontar enquanto também paradigmática de uma clínica das psicoses na infância. Apesar de todos os impasses que ressaltamos como integrantes de seu tratamento, e que demandaram um manejo específico a cada vez, pudemos acompanhar a importância que há, para a criança com sintomas psicóticos e que acaba se estruturando como psicótica, no encontro com um psicanalista. Faz toda uma diferença ter um interlocutor diante do qual é possível ocupar um lugar de palavras. A experiência psicanalítica funda este lugar, muitas vezes consistindo no único em que o sujeito pode encontrar algum reconhecimento, o que lhe é essencial para se manter fora de crise e sem o imperativo das passagens ao ato. É de extremo valor no desenrolar de seu destino, para um psicótico, o fato de ter compartilhado com alguém a montagem de uma metáfora delirante, que permite a circulação no universo fálico mesmo não dispondo do operador do Nome-do-Pai.

Nesse ponto, podemos situar um último impasse, ligado à responsabilidade na condução da análise de um psicótico, na qual nos engajamos desde sua infância, quando é o caso: a disponibilidade permanente para a escuta deste paciente, que situou no analista o garante do Outro, função indispensável para sua circulação no campo social.

\section{REFERÊNCIAS BIBLIOGRÁFICAS}

Klein, M. (1930). A importância da formafĩo de simbolos no desenvolvimento do ego. Contribuiçôes à psicanálise. São Paulo; SP: Mestre Jou, 1981.

Lacan, J. (1964). O seminírio, Livro XI, Os quatro conceitos fundamentats da psicanálise. Rio de Janeiro, RJ: Jorge Zahar, 1979.

Laznik-Penot, M.-C. (1997). Rumo à palavra - três crianças autistas em psicanálise. São Paulo, SP: Escuta.

\section{NOTA}

1 Referência a parábola de Antoine de Saint-Exupéry, $O$ pequeno príncipe.

Recebido em setembro/2001. 